\title{
Taxonomy and the DNA Barcoding Enterprise
}

\author{
MALTE C. EBACH \\ Evolution \& Ecology Research Centre, School of Biology, Earth \& Environmental Sciences, The University of New South Wales, \\ Kensington, NSW, Australia.Email: mcebach@unsw.edu.au
}

DNA Barcoding is elusive to many taxonomists. Like the numbers in a barcode, barcoding attempts to link a type specimen with a part of its DNA, most commonly from the mitochondrial Cytochrome c Oxidase subunit I (COI) gene.

Imagine a sequence of nucleotide DNA common in every organism, which has enough differences to distinguish the code of one type specimen from another. Take a sample from the type specimen of every known species and add them to a database. The result, a inventory of COI genes, can be accessed at anytime to identify specimens, either in the field or in the lab. For many, this sounds too good to be true.

Apart from the practical aspects of extracting DNA from organisms in the field, the cost and the problems associated with a limited taxonomic key based on a limited number of genes, barcoding is not something that would attract taxonomists or even amateur enthusiasts (e.g., bird watchers) (Ebach \& Holdrege, 2005a,b). Taxonomists are trained to identify as well as describe organisms through observation and have little use for barcodes. Birdwatchers, who take great pleasure in being able to identify birds without a field guide, would be horrified at distressing birds through capturing, handling and extracting DNA (contra Janzen, 2010). Who, then, would embrace DNA barcoding?

DNA barcoders have no trouble in telling us the multitude of uses of barcodes. Ranging from identifying the sources of food substitution or contamination, the presence of Genetically Modified Organisms (GMO), to the types of birds that end up minced in jet engines (Wong \& Hanner 2008; Grant 2007). There is no doubt that these are incredibly valuable uses for DNA barcoding, but nowhere do we find its uses for taxonomy. Rather we are told of the impediments to taxonomy, that is, the inability for taxonomy to provide an information service to ecologists, molecular systematists and an entire service industry that is required to identify contaminants, GMOs and hapless pâté du foie turbine. The proposed solution, it appears, is to re-vamp taxonomy as a service industry to provide ready identification and classifications for non-taxonomists. In doing so, this would liberate other fields, such as ecology, to practise species identification without any taxonomic training. Over time this policy creates a group of people often referred to as parataxonomists, who undertake to collect samples of specimens from around the globe without any context to classification (Smith et al. 2005). Extracted barcodes from these samples are databased and added into the inventory, which in turn creates new data points for other parataxonomists, and so on. Many taxonomists not directly involved in parataxonomy find themselves largely responsible for addressing specimens which have unidentifiable barcodes (often assumed to mean 'new species') or revising problematic taxonomic groups in order to streamline classifications. I guess most readers of Zootaxa would be cringing as they read this. But let us leave the practise and uses of barcoding to one side and investigate what the role of a taxonomist is in the DNA barcoding Enterprise.

Industry adheres to business plans. Without a well thought out and detailed plan, there is no way to cost a project or product. The DNA Barcoding Enterprise, which was at first funded by government-industry partnerships like Genomics Canada and the Department for Environment, Food and Rural Affairs (DEFRA) in the United Kingdom, relies on taxonomists to provide expertise to identify organisms and to quality check that barcodes accurately identify the organisms that they represent (Ebach \& de Carvalho, 2010). The payoff for the taxonomist is funding and an elevated importance in their home institution. Moreover, industry pundits have helped to intellectualise DNA barcoding as a scientific pursuit, rather than a simple technology with limited use in the biological sciences. This has in turn created a favourable 'intellectual culture' right in the heart of natural history museums (Savolainen et al. 2005). Rather than hire taxonomists, museums can now hire parataxonomists and barcoders at a fraction of the cost of training taxonomists.

The DNA Barcoding Enterprise is a success. An industry and end-user community requirement, namely species identifications, has been intellectualised within an established scientific field (i.e., taxonomy) and is funded independently via government. Ironically, industry no longer has to spend a penny to procure barcoding data and taxonomic expertise, while at the same time taxonomy and taxonomic expertise is slowly dying off. 


\section{Acknowledgements}

I thank Melinda L. Tursky and two anonymous reviewers.

\section{References}

Ebach, M. \& Carvalho, M. (2010) Anti-intellectualism in the DNA Barcoding Enterprise. Zoologia (Curitiba, Impresso), 27, 165-178.

Ebach, M. \& Holdrege, C. (2005a) DNA barcoding is no substitute for taxonomy. In: Nature, 434, 697-697.

Ebach, M. \& Holdrege, C. (2005b) More taxonomy, not DNA barcoding. In: BioScience, 55, 823-824.

Grant, B. (2007) Cataloging Life. The Scientist, 21(12), 36. Available online at: http://www.the-scientist.com/article/display/ 53881 [Accessed: 06/04/2010].

Janzen, D.H. (2010) Hope for Tropical Biodiversity through True Bioliteracy. Biotropica, 42, 540-542.

Savolainen, V., Cowan, R., Vogler, A., Roderick, G. \& Lane, R. (2005) Towards writing the encyclopaedia of life: an introduction to DNA barcoding. Philosophical Transactions of the Royal Society B: Biological Sciences, 360, 1805.

Smith, M., Fisher, B. \& Hebert, P. (2005) DNA Barcoding for Effective Biodiversity Assessment of a Hyperdiverse Arthropod Group: The Ants of Madagascar. Philosophical Transactions: Biological Sciences, 360, 1825-1834.

Wong, E. \& Hanner, R. (2008) DNA barcoding detects market substitution in North American seafood. Food Research International, $41,828-837$. 